\title{
T. D. WILSON E SUA CONTRIBUIÇÃO À CIÊNCIA DA INFORMAÇÃO: ANÁLISE SOBRE O CONCEITO DE COMPORTAMENTO INFORMACIONAL
}

\begin{abstract}
Resumo: Aborda a contribuição e a aplicação teórica dos modelos de Comportamento Informacional desenvolvidos por T. D. Wilson. De cunho exploratório, realizada a partir de levantamento bibliográfico sobre o tema na Base Referencial de Artigos de Periódicos em Ciência da Informação (BRAPCI), a pesquisa investiga a utilização da temática segundo a quantidade de vezes que o termo foi abordado em artigos datados desde 1997. Com a análise, foi possível verificar o crescimento de publicações que versam sobre a temática na última década, bem como a ampla citação do modelo teórico elaborado por T. D. Wilson, em mais da metade dos artigos recuperados no âmbito da Ciência da Informação (CI), tanto em pesquisas básicas como aplicadas. Assim, as propostas teórico-conceituais de T. D. Wilson fornecem aportes aos estudos sobre comportamento informacional.
\end{abstract}

Palavras-chave: Ciência da Informação. Estudos de Usuários. Comportamento Informacional. T. D. Wilson.

\author{
Fernando Santos da Silva \\ Mestre Ciência da Informação pela \\ Universidade Federal do Ceará (UFC). \\ fernandosantosce1@gmail.com \\ Damaris Queiroz Barreto \\ Mestre Ciência da Informação pela \\ Universidade Federal do Ceará (UFC). \\ damarisqueirozb@gmail.com \\ Jefferson Veras Nunes \\ Professor do Programa de \\ Pós-Graduação em Ciência da \\ Informação da Universidade Federal do \\ Ceará (UFC). \\ jefferson.veras@yahoo.com.br \\ Lidia Eugênia Cavalcante \\ Professora do Programa de \\ Pós-Graduação em Ciência da \\ Informação da Universidade Federal do \\ Ceará (UFC). \\ cavalcantelidiaeugenia@gmail.com
}

\section{T. D. WILSON AND YOUR CONTRIBUTION TO INFORMATION SCIENCE: ANALYSIS ABOUT THE CONCEPT OF INFORMATION BEHAVIOR}

\begin{abstract}
It approaches the contribution and the theoretical application of the Information Behavior models developed by T. D. Wilson. It treats of an exploratory research, carried out from a bibliographic survey on the Reference Database of Articles of Periodicals in Information Science (BRAPCI), where it was sought to investigate the use of the thematic according to the number of times the term has been covered in articles since 1997. With the analysis, it was possible to verify the growth of publications that deal with the subject in the last decade, as well as the broad citation of the theoretical model elaborated by T. D. Wilson in more than half of the articles recovered within the scope of Information Science, both basic and applied research. Therefore, the theoretical-conceptual proposals of T. D. Wilson provide contribution to the research about information behavior.
\end{abstract}

Keywords: Information science. User studies. Information behavior. T. D. Wilson.

\section{INTRODUÇÃO}

As abordagens que permeiam os estudos sobre como as pessoas buscam e usam informação passaram por diversas mudanças ao longo da história da Ciência da Informação (CI). Tendo um início bastante ligado à informação científica, as primeiras pesquisas realizadas no âmbito da Ciência da Informação voltavam-se para problemas de comunicação 
entre os cientistas e profissionais de uma determinada área; com o tempo, desenvolveu-se no campo abordagens próximas às ciências cognitivas, a partir das quais a informação passa a ser definida como aquilo que provoca mudanças no modo como as pessoas percebem o mundo, residindo, contudo, numa perspectiva individualista; em contraponto, há, atualmente, o desenvolvimento de uma linha de pensamento que considera o indivíduo como pertencente a uma comunidade, a qual possibilita levar em conta questões sociais e culturais mais amplas na relação que as pessoas estabelecem com a informação.

Os estudos sobre como as pessoas buscam e usam informação também passaram por transformações ao longo do tempo. No início, as investigações centravam no uso dos sistemas. Recentemente, voltado para o indivíduo, as pesquisas têm lidado com o conceito de comportamento informacional com o intuito de abordar questões relacionadas às necessidades de informação dos sujeitos em diferentes contextos. Trata-se, portanto, de uma mudança de perspectiva onde prevalecem mais os indivíduos e menos os sistemas.

Tendo como bojo os estudos de usuários, a preocupação acerca do sujeito foi paulatinamente conquistando força a partir de desenvolvimentos teórico-conceituais que contribuíram para o estabelecimento de um programa de pesquisa mais amplo, de cunho interdisciplinar, relacionado à informação. Nesse sentido, T. D. Wilson é reconhecido como um dos autores que contribuíram fortemente para essa virada epistemológica, sendo considerado ainda como um dos precursores da ideia de comportamento informacional, tornando-se referência em estudos no âmbito da Ciência da Informação desde a década de 1980.

Com base nisso, o objetivo do presente artigo é analisar a presença do conceito de comportamento informacional e suas influências na Ciência da Informação. Recorre-se a artigos de periódicos disponibilizados na Base Referencial de Artigos de Periódicos da Ciência da Informação (BRAPCI), com a finalidade de entender tanto a relevância da temática para a área, como, também, discutir o escopo da utilização e disseminação dos modelos elaborados e difundidos por T. D. Wilson.

\section{O COMPORTAMENTO INFORMACIONAL E OS MODELOS DE T. D. WILSON}

A Royal Society Information Scientific Conference, realizada em 1948, é considerada 
como um dos marcos dos estudos sobre a busca e o uso da informação pelos indivíduos. As pesquisas divulgadas no evento voltavam-se para o uso das bibliotecas, sem abordar problemas relacionados a necessidades informacionais; o foco, por sua vez, residia no estabelecimento de perfis dos usuários. Ainda assim, conforme Wilson (2000), foi justamente nesse período que começou a haver uma preocupação no tocante ao modo como os indivíduos lidavam com a informação em suas áreas de atuação, mais especificamente nos campos da ciência e da tecnologia.

Uma década depois, na International Conference on Scientific Information, em Washington, trabalhos que tratando mais explicitamente das necessidades informacionais dos pesquisadores dentro de seus respectivos campos foram apresentados tendo como eixo preocupações voltadas à estruturação de serviços de referência com maior efetividade. Inquietações com aspectos humanos da busca e do uso da informação ainda não foram contempladas. No cerne do debate permaneciam os sistemas e recursos informacionais com os quais lidavam os médicos, cientistas das áreas ambientais e da indústria atômica, por exemplo (WILSON, 1999, 2000).

Segundo Choo (2003, p. 67),

\begin{abstract}
Os primeiros estudos foram, em sua maioria, patrocinados por associações profissionais, que precisavam elaborar seus programas para responder à explosão de informações científicas e novas tecnologias. Esses estudos também eram iniciados por bibliotecários ou administradores de centros de informação ou laboratórios, que precisavam de dados para planejar seu serviço.
\end{abstract}

Percebe-se uma aproximação entre a chamada abordagem tradicional dos estudos de usuário e o chamado paradigma físico que se instaurava na Ciência da Informação, residindo o foco nas estatísticas relacionadas ao uso dos recursos informacionais, de modo que fosse possível obter padrões de comportamento visando a avaliação dos serviços e sistemas de informação. Ferreira (1995) destaca que a informação, nessa abordagem, era frequentemente caracterizada como algo externo ao indivíduo, evidenciando forte influência da Teoria da Informação, de Shanon e Weaver (1949).

$\mathrm{Na}$ Teoria da Informação, o processo comunicacional é composto por um emissor, por um canal pelo qual se transmite a mensagem e por um receptor. A informação, nessa visão, é tida como componente da mensagem enviada, podendo ser medida a partir de sua capacidade de reduzir incertezas. A informação adquire uma dimensão "[...] objetiva, independente dos 
usuários e dos sistemas sociais" (CHOO, 2003, p. 68). Todavia, questões no tocante à relação entre indivíduo e informação começaram a exigir, com o tempo, mudanças na forma como eram propostas. Paulatinamente, os estudos passam a se deslocar dos sistemas para dar início a preocupações voltadas aos aspectos subjetivos no surgimento da necessidade, busca e uso da informação.

Um primeiro esforço empreendido nesse sentido recebeu a denominação de abordagem cognitiva, o qual se caracterizou por defender a ideia de informação enquanto recurso à resolução de um problema ou ao preenchimento de uma lacuna cognitiva, levando o sujeito a buscar a informação necessária para suprir essa demanda. Uma questão que afetou as reflexões sobre essa temática relacionava-se a dificuldades empíricas e instrumentalização dos conceitos, favorecendo também a utilização de métodos predominantemente quantitativos.

Com isso, a análise do comportamento humano durante a busca enfatizava a objetividade e a neutralidade, prevalecendo mais o aspecto individual e menos o contexto social das necessidades dos indivíduos. Ainda assim, a partir da adoção de métodos qualitativos e indutivos, uma postura mais abrangente quanto às necessidades informacionais foi adquirindo um ponto de vista também sociológico (GASQUE; COSTA, 2010).

Inicialmente, não houve preocupação com a conceituação do termo comportamento informacional. É só no final da década de 1990 que T. D. Wilson começa a apontar a importância do debate sobre o termo, definindo-o a partir dos processos que circundam a necessidade, a busca e o uso da informação (GASQUE; COSTA, 2010; WILSON, 1999). Complementando, Martinez-Silveira e Oddone (2007) afirmam que "comportamento informacional" alude à percepção de manifestações externas de processos mentais durante a busca ou verbalização de uma necessidade.

Assim, pode-se dizer que necessidade informacional é outro termo que possui lugar de destaque na discussão sobre comportamento informacional. Cunha, Amaral e Dantas (2015) afirmam que:

As necessidades de informação são de tipos variados. Alguns indivíduos precisam encontrar um documento específico com dados descritivos conhecidos ou necessitam encontrar documentos sobre um determinado tema. Outros querem solucionar um problema específico. Uns necessitam de atualização corrente, enquanto outros precisam de um simples dado ou informação factual. Também existem aqueles que solicitam que a informação seja obtida após a consulta a mais de um tipo de documento (CUNHA; AMARAL; DANTAS, 2015, p. 3). 
Para Line (1974), necessidade deve ser compreendida como algo que o indivíduo considera fundamental ao desenvolvimento de suas atividades, podendo se fazer presente nas esferas da pesquisa para atender a propósitos pessoais ou até em práticas de lazer. Além disso, cabe ressaltar ainda que a necessidade pode exprimir valores da sociedade:

\footnotetext{
Estritamente, uma necessidade é algo necessário, alguma coisa que a pessoa não pode ficar sem. Porém, quem pode afirmar o que é necessário para si próprio ou para outra pessoa? O dizer 'alguém necessita informação' se confunde com o dizer 'alguém necessita tomar banho'. Tanto informação como banho são úteis, mas nem sempre absolutamente essenciais (LINE, 1974 apud CUNHA; DANTAS; AMARAL, 2015, p. 4).
}

Portanto, as necessidades são dotadas de complexidades que perpassam um entendimento do contexto do seu surgimento, bem como as motivações do indivíduo, dentre outros fatores. Para isso, os modelos podem auxiliar na identificação dessas variáveis no âmbito de um conjunto de processos mais amplos, possibilitando definir desde metodologias, instrumentos de coleta de dados ou de análises a partir do que for percebido no ambiente de investigação.

Em definição do próprio T. D. Wilson (1999), os modelos podem ser vistos como estruturas de pensamento sobre determinado problema e devem envolver o estabelecimento de um relacionamento entre proposições teóricas. Na Ciência da Informação, os modelos formaram algumas bases de estudo sobre comportamento informacional. Ainda que haja destaque a esses modelos, eles têm apenas servido para a descrição, na forma de diagramas, das atividades de busca informacional, bem como causas, consequências e fatores que influenciam no processo e seus estágios, sem avançar em aspectos mais aprofundados que possibilitem a construção efetiva de um corpo teórico-conceitual.

O primeiro modelo sobre comportamento informacional de T. D. Wilson foi publicado originalmente em 1981, sendo revisado anos depois (Figura 1). Nele, o comportamento de busca de informação surge como consequência de uma necessidade. Com isso, o indivíduo recorre a recursos formais (sistemas de informação) ou informais (recursos que não têm a função inicial de fornecer informações) e essa busca pode ser bem-sucedida ou apresentar falhas ao longo do seu processo. Nesse modelo, são levadas em conta também as trocas informacionais com outras pessoas (Information exchanges), portanto o comportamento de 
busca informacional não é restrito apenas a interação entre usuários e sistemas (WILSON, 1999, 2006).

Segundo T. D. Wilson (2006), ainda não há uma definição clara do que são essas necessidades (need), o que pode estar relacionado à complexa tarefa que é considerar o contexto do qual decorrem tais necessidades. As limitações desse modelo, segundo o próprio autor, estão relacionadas ao fato de não apontar nenhum fator que possa ocasionar o comportamento informacional, ou seja, não esclarece em que momento ou a partir de qual motivação surge uma necessidade, não havendo também qualquer menção sobre o contexto e como ele pode influenciar nesse processo (WILSON, 1999).

Figura 1: Modelo de comportamento informacional de T. D. Wilson de 1981

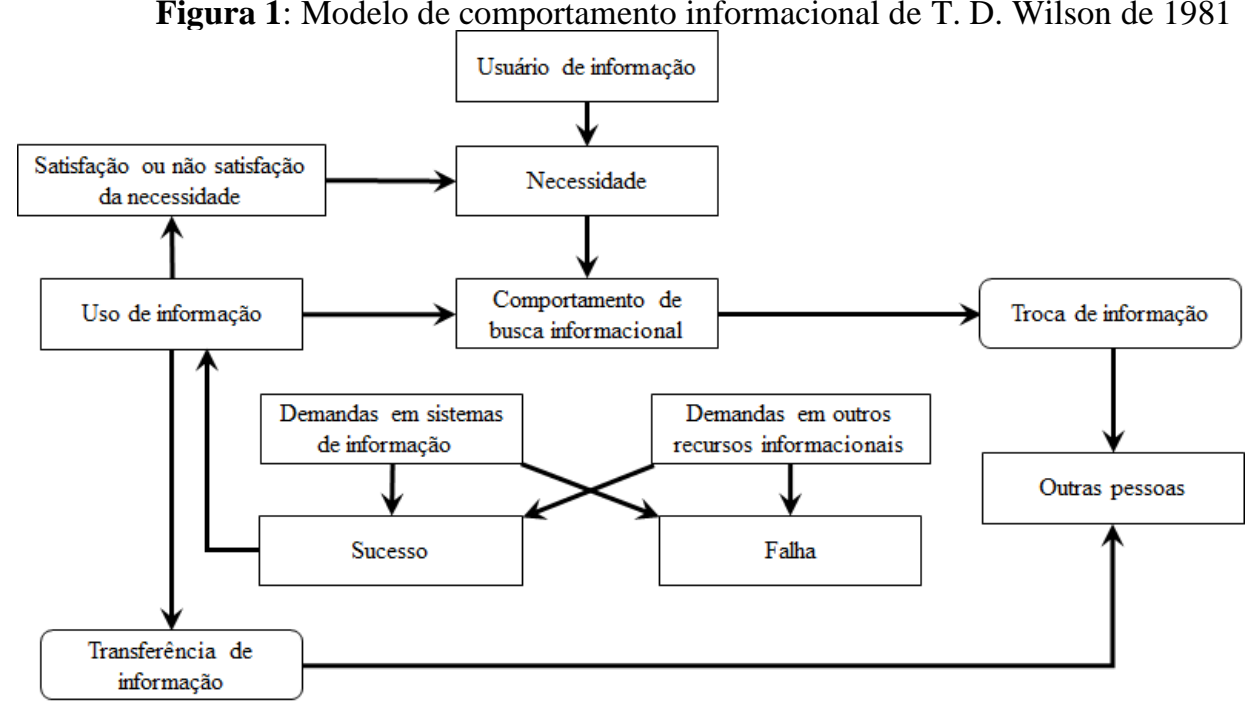

Fonte: adaptado de T. D. Wilson (1999).

Um segundo modelo foi elaborado por T. D. Wilson, denominado Modelo de Comportamento de Busca de Informação (Information-Seeking Behavior) (Figura 2). Mesmo contanto com algumas diferenças, o autor decidiu conservar a estrutura básica do modelo anterior. Sua estrutura tem como base duas premissas, a saber: as necessidades informacionais não são necessidades primárias; e, na intenção de satisfazer determinada demanda, o indivíduo pode enfrentar barreiras de diferentes tipos (WILSON, 1999).

Nesse modelo percebe-se níveis diferentes de necessidades informacionais correspondendo, no esquema, às indicações Ambiente, Papel social e Pessoal - podendo, contudo, surgir simultaneamente. Isso não impede com que as pessoas se engajem em um 
processo de busca de informação visando satisfazer questões primárias ao mesmo tempo em que estejam desenvolvendo uma busca correspondente ao contexto ambiental ou ao seu papel social. Vale salientar que, nessa versão do modelo, são considerados aspectos relacionados ao comportamento de busca de informação durante a utilização de sistemas, englobando também os sistemas informais, considerados como fontes não tradicionais de informação. Mesmo sendo mais abrangente que o modelo anterior, T. D. Wilson (1999) assinala como fragilidades desse modelo (Figura 2) o fato de não expor claramente quais são os processos ou barreiras que interferem nas necessidades informacionais de um indivíduo.

Figura 2: Modelo de comportamento de busca de informação de T. D. Wilson de 1981

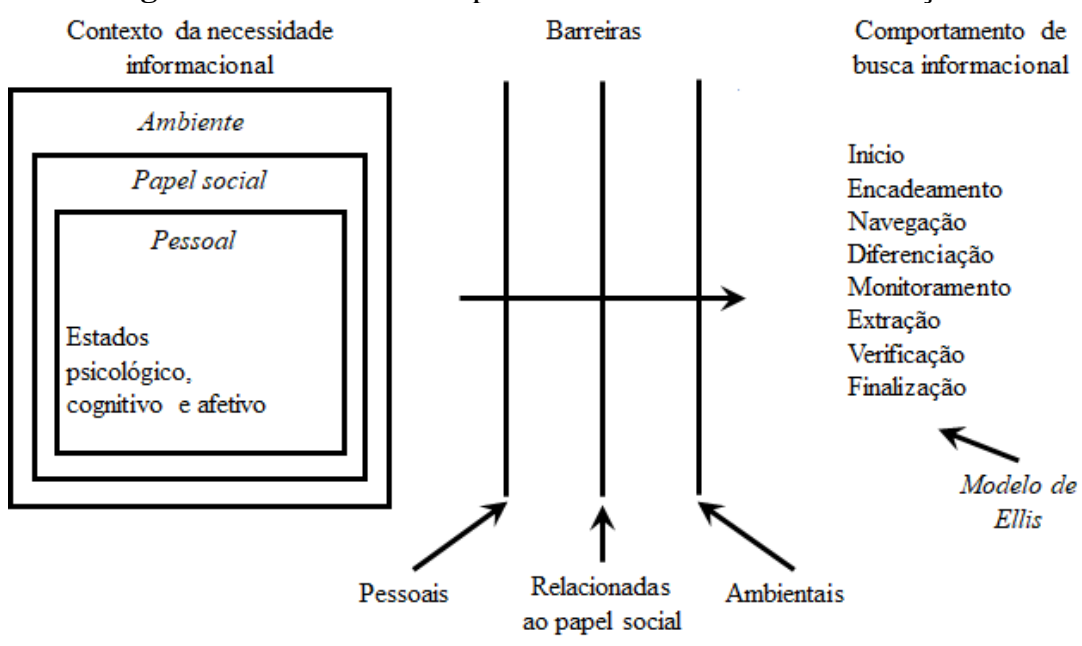

Fonte: adaptado de T. D. Wilson (1999).

Em 1996, T. D. Wilson elabora um terceiro modelo (Figura 3) a partir de uma revisão dos anteriores, incluindo aspectos de outros campos. Embora o indivíduo seja compreendido a partir de um contexto, as barreiras são representadas por "variáveis intervenientes" (Intervening variables). Essa visão passa a tratar as barreiras enquanto fatores que tanto podem auxiliar, como impedir o uso da informação. Além disso, considera ainda outros tipos de comportamento de busca de informação, e não só a "busca ativa", que era o foco dos modelos anteriores (WILSON, 1999).

O modelo traz como novidade o fato do processamento e uso da informação servirem como retroalimentação do sistema, mostrando como a necessidade foi satisfeita e como isso foi realizado. A partir daí, são apresentadas três postulações teóricas: a primeira refere-se à teoria do estresse ou enfrentamento (Stress/coping theory), a qual ajuda a explicar porque 
algumas necessidades informacionais não provocam o comportamento de busca de informação; a segunda diz respeito à teoria do risco ou recompensa (Risk/reward theory), que contribui para a explicação sobre quais recursos informacionais podem ser mais utilizados do que outros por um indivíduo; e, por fim, a terceira alude à teoria do aprendizado social (Social learning theory), englobando o conceito de autoeficácia (Self-efficacy), que corresponde à certeza de que o indivíduo pode desenvolver o comportamento necessário para produzir os resultados almejados (WILSON, 1999).

Figura 3: Modelo de comportamento informacional de T. D. Wilson de 1996

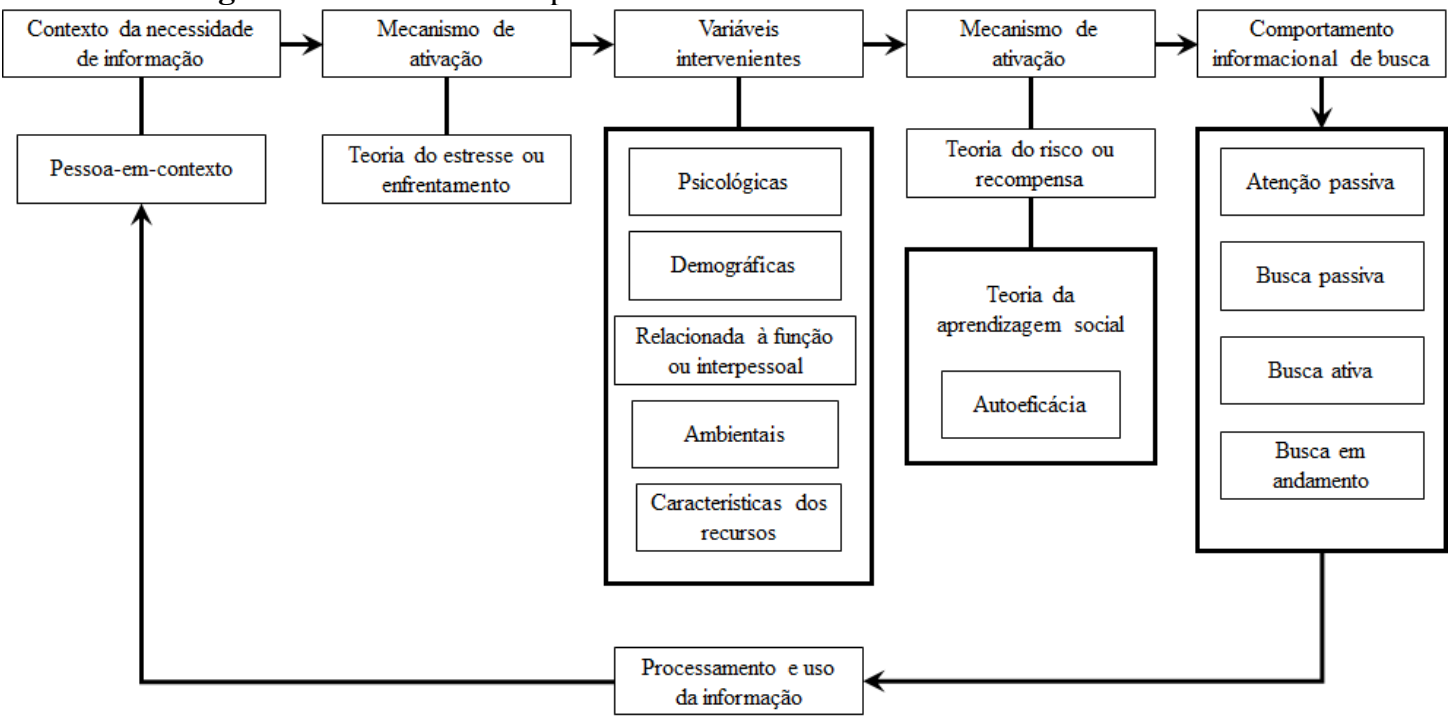

Fonte: adaptado de T. D. Wilson (1999).

Analisando os modelos de T. D. Wilson, percebe-se como os estudos de comportamento informacional se desenvolveram com o passar do tempo de modo a considerar diferentes fatores relacionados à busca e uso da informação, abordando desde questões psicológicas até sociais.

\section{ANÁLISE E DISCUSSÃO DOS RESULTADOS}

A pesquisa é de abordagem exploratória, abrangendo um ponto de vista dentro de um universo mais amplo, podendo servir como aporte para trabalhos futuros com maior aprofundamento (GIL, 2008). Assim, procedeu-se, inicialmente, com uma pesquisa bibliográfica, focada nos artigos científicos indexados na Base Referencial de Artigos de 
Periódicos em Ciência da Informação (BRAPCI). A amostragem foi estabelecida a partir do critério intencional (MARCONI; LAKATOS, 2014), a partir da qual se definiu o intervalo de 10 anos para os artigos recuperados, indo de 1997 a 2017, com o objetivo de identificar a ocorrência de abordagens dos modelos e das discussões, no âmbito da Ciência da Informação, baseadas na obra de T. D. T. D. Wilson.

Para isso, foi realizado um levantamento na BRAPCI durante o mês de dezembro de 2017. No campo de busca do site inseriu-se o termo "comportamento informacional" entre aspas e sem qualquer outra filtragem oferecida pelo sistema. Dentro do intervalo definido (1997-2017), foram recuperados 73 artigos distintos, distribuídos em 24 periódicos.

A Tabela 1, fornecida pela própria plataforma da BRAPCI, apresenta os títulos dos periódicos aos quais pertencem as publicações, estando ordenados de acordo com o número de artigos, indo da maior para a menor ocorrência. O periódico Perspectivas em Ciência da Informação figurou como aquele com mais publicações sobre a temática.

Tabela 1: Títulos dos periódicos recuperados na BRAPCI

\begin{tabular}{|c|c|}
\hline Título do periódico & $\begin{array}{c}\text { Quantidade de } \\
\text { artigos recuperados }\end{array}$ \\
\hline Perspectivas em Ciência da Informação & 10 \\
\hline Econtros Bibli & 7 \\
\hline Informação \& Sociedade: Estudos & 6 \\
\hline Ciência da Informação & 6 \\
\hline Informação \& Informação & 6 \\
\hline Revista ACB: Biblioteconomia em Santa Catarina & 4 \\
\hline Múltiplos Olhares em Ciência da Informação & 4 \\
\hline Brazilian Journal of Information Science & 3 \\
\hline Em Questão & 3 \\
\hline InCID & 3 \\
\hline Revista Digital de Biblioteconomia \& Ciência da Informação & 3 \\
\hline Biblionline & 2 \\
\hline BIBLOS & 2 \\
\hline DataGramaZero & 2 \\
\hline Tendências da Pesquisa Brasileira em Ciência da Informação & 2 \\
\hline Transinformação & 2 \\
\hline Ágora & 1 \\
\hline Archeion Online & 1 \\
\hline Biblioteca Escolar em Revista & 1 \\
\hline Encontro Nacional de Pesquisa em Ciência da Informação & 1 \\
\hline Informação Arquivística & 1 \\
\hline Informação em Pauta & 1 \\
\hline Ponto de Acesso & 1 \\
\hline Revista Eletrônica de Comunicação, Informação \& Inovação em Saúde & 1 \\
\hline Total & 73 \\
\hline
\end{tabular}

Fonte: dados da pesquisa. 
A segunda fase consistiu na distinção entre os artigos que citam ou não T. D. Wilson, fazendo uma filtragem daqueles que trabalham com seus postulados. 34 trabalhos não fazem qualquer menção ao autor, o que representa $47 \%$ do total recuperado. Os outros $53 \%$ fazem citações dele ora no referencial teórico, ora na descrição dos modelos de aplicação na pesquisa. Por esses dados, o autor possui sim relevância quando se trata do assunto comportamento informacional, visto que em praticamente metade dos artigos ele é acionado de alguma forma.

O Gráfico 1 exemplifica essa questão, mostrando o número de artigos que citam T. D. Wilson em comparação àqueles que tratam de comportamento informacional, separados por ano.

As barras em azul representam o número de artigos que abordam a temática comportamento informacional (73) em cada ano indicado. As barras em laranja se referem à quantidade de artigos que mencionam T. D. Wilson (39). Nota-se uma presença relevante do autor no total das pesquisas publicadas por ano, em comparação a todos os assuntos que tratam acerca do tema.

Gráfico 2: Ano de publicação dos artigos

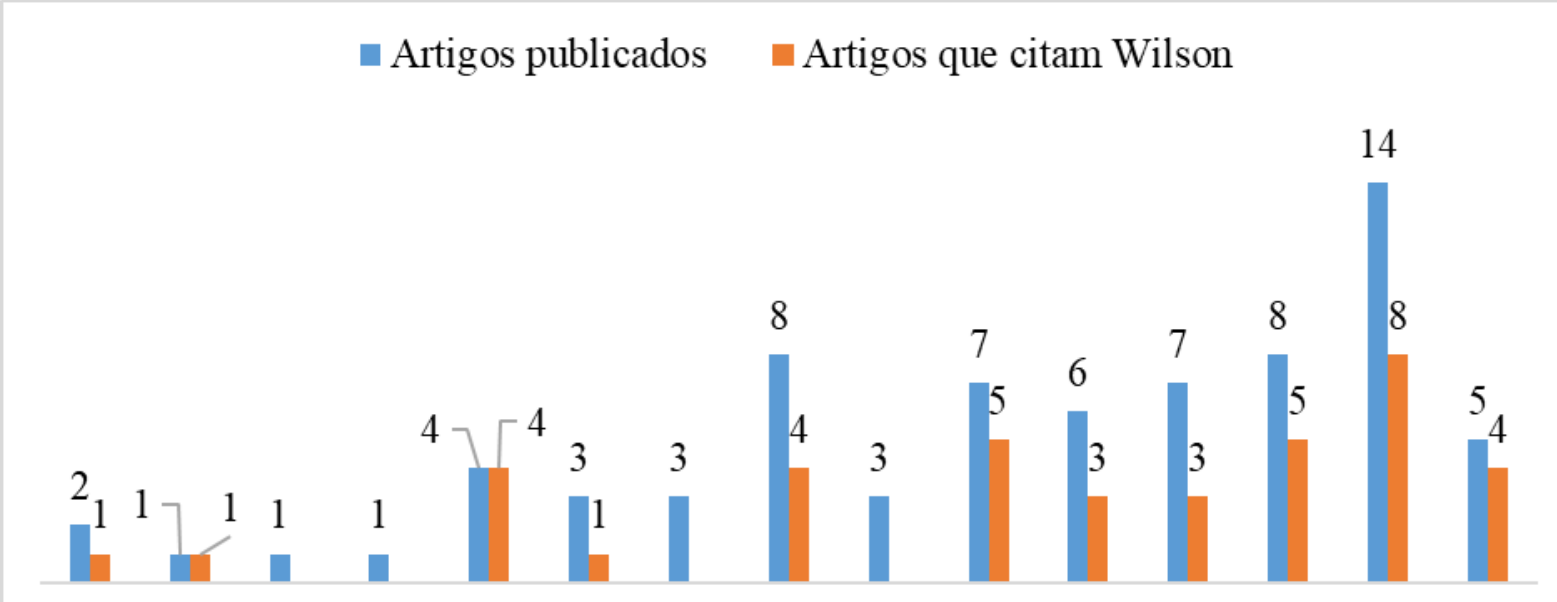

199720032005200620072008200920102011201220132014201520162017

Fonte: dados da pesquisa.

Na Tabela 2 são apresentados os 39 artigos que se encaixaram nos critérios dessa segunda fase. 
Tabela 2: Artigos que citam T. D. Wilson

Autores
ROMAGNOLI, A. R.;
BARTALO, L.
AKAICHI, T. et al.
SILVA, A. M. M.; MARCIAL, V.
F.

ARANTES, F. M. et al.

ARAÚJO, C. A. Á.

BARBOSA, R. R.

BERTI, I. C. L. W.; ARAÚJO, C. A. Á.

BERTI, I. C. L. W.; BARTALO, L.; ARAÚJO, C. A. Á.

CARDOSO, A. M. P.; RODRIGUES, V. L.

CAVALCANTE, R. B. et al.

CHAGAS, L. de D.; COSTA, S. M. de S.

COSTA, L. F. da; RAMALHO, F. A.

COSTA, M. N. da et al.

CRESPO, I. M.; CAREGNATO,

S. E.

CRUZ, R. do C.; SILVEIRA, J. G. da

FIALHO, J. F.

FIALHO, J. F.; ANDRADE, M. E. A.

FIGUEIREDO, D. A.; PAIVA, E. B.

FURTADO, R. L. et al.

GAMA, F. A. da; FERNEDA, E. GANDRA, T. K.; DUARTE, A. B S.
Título

O comportamento informacional de advogados trabalhistas no processo judicial eletrônico

Comportamento informacional no uso de sistemas de informação: o caso do SICOR

Alfabetização informacional em Portugal: alguns resultados de um projeto de pesquisa

O comportamento informacional dos canais informais de comunicação por meio da oralidade

Estudos de usuários da informação: comparação entre estudos de uso, de comportamento e de práticas a partir de uma pesquisa empírica

Acesso e necessidades de informação de profissionais brasileiros: um estudo exploratório

Estudos de Usuários e Práticas Informacionais: do que estamos falando?

Comportamento informacional de pais de crianças com Síndrome de Down

O campo de estudos de usuários na Ciência da Informação brasileira: uma revisão sistemática da literatura

Comportamento informacional de gestores da rede Hiperdia Minas

Efetividade do processo de comunicação com base na abordagem do comportamento informacional: o caso de um organismo internacional da área da saúde pública sediado no Brasil

Religare: comportamento informacional à luz do modelo de Ellis

Comportamento informacional das comunidades acadêmica e organizacional da Universidade Estadual de Londrina

Comportamento de busca de informação: uma comparação de dois modelos

Redes sociais virtuais de informação sobre amor

Ações, pensamentos, sentimentos e estratégias no processo de pesquisa acadêmica

Comportamento informacional de crianças e adolescentes: uma revisão da literatura estrangeira

Estudo do comportamento informacional dos usuários da Médiathèque Simone de Beauvoir da Aliança Francesa João Pessoa

Comportamento informacional de usuários de um telecentro

A mediação da informação nos arquivos permanentes: serviços de referência arquivística no ambiente digital.

Usuário da informação sob a perspectiva metodológica: revisão de literatura e proposta de postura metodológica de pesquisa 
GASQUE, K. C. G. D.; COSTA, S. M. de S.

LAGE, S. R. M. et al.

SECO, L. F. C.; SANTOS, Z. P. dos; BARTALO, L.

MANABE, V. M. M. L. et al.

MARTÍNEZ-SILVEIRA, M. S.; ODDONE, N. E.

CORREA, M. de V.; ROZADOS, H. B. F.

OLIVEIRA, M. U. M.; BERNDT, A.; RIBEIRO, X.

ROCKEMBACH, M.

NASCIMENTO, M. S.;

VITORIANO, M. C. de C. P.

NASSIF, M. E.; VENÂNCIO, L. S.; HENRIQUE, L. C. J.

PEREIRA, F. C. M.

ZAIDAN, P. et al.

PIRES, E. A. de N.

PRESSER, N. H.; SILVA, M. L. da

SANTOS, A. P. dos; CALDAS, F. C.

SILVA, H. de C.; OLIVEIRA, E. S. de

SORDI, J. O. de; AZEVEDO, M. C. de; MEIRELES, M. A.

TABOSA, H. R.; PINTO, V. B.
Evolução teórico-metodológica dos estudos de comportamento informacional de usuários

O comportamento informacional no estágio curricular

Comportamento informacional e compartilhamento da informação no Instagram

Comportamento informacional de ingressantes e concluintes de um curso superior

Necessidades e comportamento informacional: conceituação e modelos

Comportamento informacional em comunidades virtuais: um estudo netnográfico do grupo de interesses SEER/OJS IN BRAZIL do Facebook

Estudo de usuários: o comportamento informacional dos alunos da UFMG doadores e não-doadores de sangue

Difusão em arquivos: uma função arquivística, informacional e comunicacional

Comportamento informacional nas organizações: a busca e o uso de informações no processo de avaliação documental

Sujeito, contexto e tarefa na busca de informação: uma análise sob a ótica da cognição situada

Fontes de informação para negócios: análise sobre frequência, relevância e confiabilidade, baseada em estudo empírico com empresários e gestores organizacionais

O Comportamento Informacional dos jogadores de League of Legends

Comportamento informacional e processo de busca da informação: bases fundamentais para pesquisa científica

Estudo do usuário da informação: o contexto e as características do trabalho dos gestores acadêmicos

Comportamento informacional e avaliação de serviços bibliotecários

O uso da informação no âmbito acadêmico: o comportanto informacional de pós-graduandos da área de Educação

Análise crítica da pesquisa em comportamento informacional segundo as demandas da empresa intensiva em conhecimento

Caracterização do comportamento de busca e uso de informação na área da Saúde: o Modelo de Ellis aplicado ao estudo do comportamento informacional de pacientes

Fonte: dados da pesquisa.

Junto a esses trabalhos que citam T. D. Wilson, buscou-se entender quantos podem ser definidos como pesquisa básica ou aplicada. Assim, é possível entender melhor a aplicabilidade dos construtos teóricos-metodológicos de T. D. Wilson. O Gráfico 3 apresenta o resultado dessa etapa. 
Constatou-se que $64 \%$ - o correspondente a 25 artigos - tratam de pesquisas aplicadas, utilizando modelos de comportamento informacional ou mesmo dos conceitos trabalhados nas discussões para estudar determinada comunidade. Representando um terço do total de abordagens do autor, o que denota a própria tendência de aplicabilidade na área, visto que a essência dos estudos em comportamento informacional é o estudo das necessidades informacionais dos indivíduos.

Gráfico 3: Natureza das pesquisas que citam T. D. Wilson

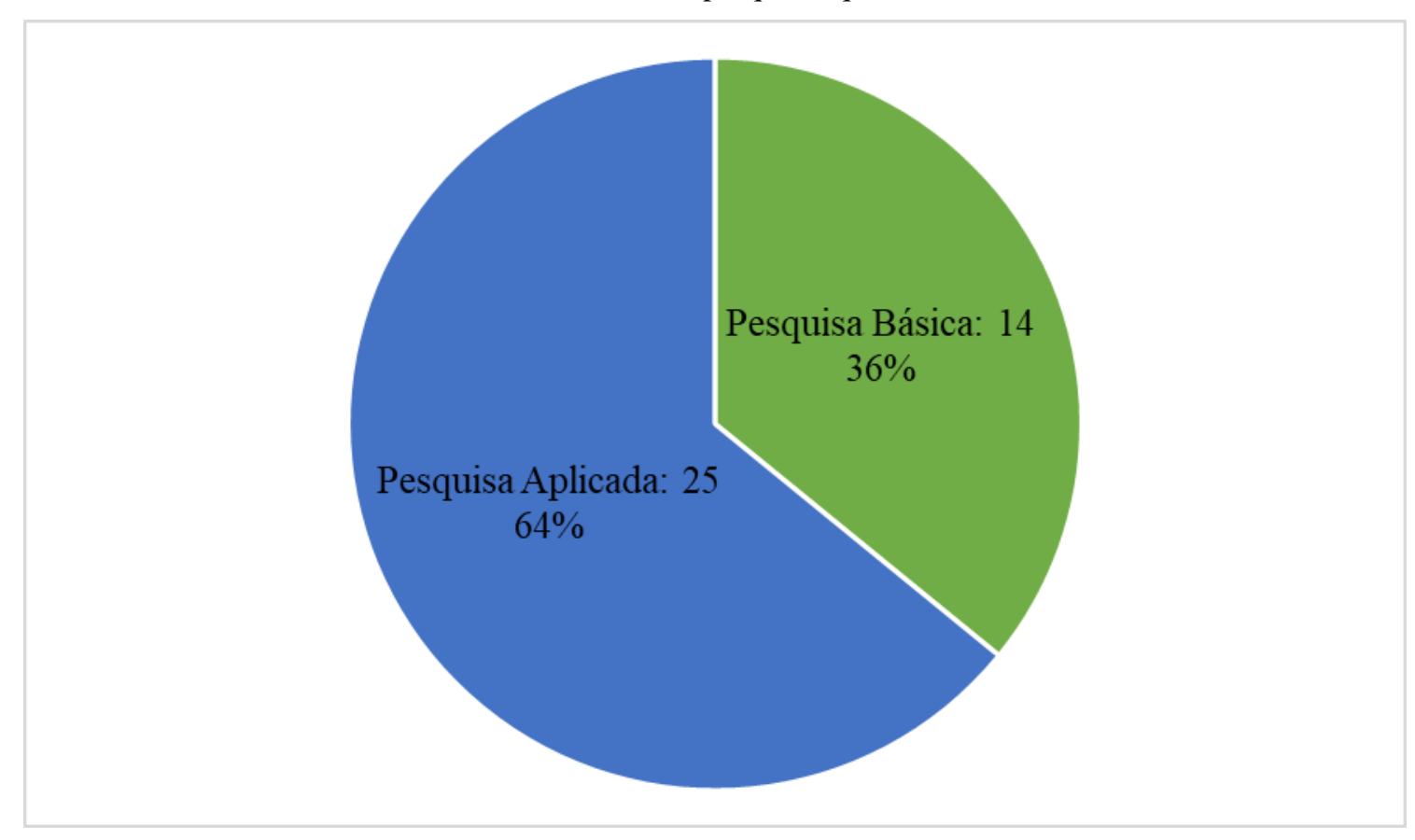

Fonte: dados da pesquisa.

Em termos de pesquisa aplicada, duas publicações servem como importante referência para se visualizar as aplicações das ideias de T. D. Wilson na Ciência da Informação. Santos e Calda (2016) trabalharam a partir do modelo de comportamento informacional concebido em 1981, utilizando-o como base à elaboração do instrumento de coleta de dados num ambiente jurídico, recorrendo a ele também para a análise dos resultados obtidos durante a pesquisa.

Já Cavalcante e outros (2017) empreendem sua pesquisa na rede do Programa Hiperdia Minas, trabalhando a perspectiva de T. D. Wilson, para a compreensão não apenas teórica da área de comportamento informacional como também, assim como Santos e Calda 
(2016), no sentido de fornecer suporte para a análise do ambiente investigado. Mais especificamente, Cavalcante e outros (2017) elaboram suas categorias de análise baseados nas dimensões que compõem o modelo de comportamento de T. D. Wilson (2000).

Ainda no tocante à categoria aplicabilidade, Nascimento e Vitoriano (2017) adotam o modelo de comportamento informacional, elaborado por T. D. Wilson em 1999, no processo de avaliação documental, justificando-o como adequado pela abrangência de seus conceitos, permitindo sua abordagem num ambiente organizacional no qual a informação é considerada como recurso importante na tomada de decisão.

Os três trabalhos acimas citados ilustram a atualidade das propostas de T. D. Wilson, além da aplicabilidade a universos diversos que não são predominantemente de pesquisa - ou seja, não focam em comportamentos informacionais desenvolvidos em ambiente científico-acadêmico. Foram os únicos artigos que fizeram a aplicação dos modelos de uma forma direta na coleta e/ou na análise dos dados. As outras publicações fazem menções do autor de forma a incrementar a discussão no referencial teórico.

Investigando a ótica dos artigos que fazem pesquisas básicas, a importância de T. D. Wilson pode ser vista nas ocasiões em que se traça um panorama histórico ou como auxílio na definição da metodologia comportamento informacional.

Gandra e Duarte (2012), por exemplo, apresentam contribuições que a fenomenologia pode oferecer à Ciência da Informação, especificamente no campo dos estudos de usuários e de comportamento informacional. É preciso pontuar que T. D. Wilson havia trazido discussões, ainda quando atuava o paradigma cognitivo, acerca da fenomenologia e da possibilidade de se utilizar seu aporte teórico-metodológico para os estudos de usuários.

Ao discutir, do ponto de vista da fenomenologia, a questão dos tipos ideais, T. D. Wilson declara que essa tipificação dos indivíduos de acordo com certos modelos forneceria uma chave para o entendimento de determinados modos de ação social. Nesse pensamento, o comportamento dos indivíduos poderia ser melhor compreendido nas ocasiões em que surgem as necessidades informacionais e, consequentemente, nos processos de busca e uso da informação (GANDRA; DUARTE, 2012).

Dessa forma, a fenomenologia, abriria possibilidades não só pela contribuição teórica, mas também, com apontado, aumentaria o escopo das investigações na área de estudo de usuários, mais especificamente, do comportamento informacional, também de um ponto de 
vista metodológico, servindo como um ponto de partida para a construção da pesquisa e fornecendo insumos para a escolha adequada dos instrumentos de coleta e de análise de dados.

No caso de Fialho e Andrade (2007), o foco da revisão está nos estudos sobre comportamento informacional de crianças e adolescentes, destacando a contribuição de autores estrangeiros. Ressaltam que somente nos últimos 25 anos é que o comportamento informacional passou a ser o foco das pesquisas. Nesse ponto, a pesquisa de Gasque e Costa (2010) também nos revela que "comportamento informacional" substituiu outras denominações utilizadas anteriormente como necessidade e uso da informação. É preciso, entretanto, reforçar que o conceito em si somente passou a ser utilizado na década de 1990 para a definição da área, antes sendo enfocado dentro dos estudos de usuários, como um termo específico da mesma forma que necessidade informacional e uso de informação.

Algumas abordagens acabam também mostrando como as pesquisas sobre esse assunto, incluindo os modelos de T. D. Wilson, são vistos dentro dos estudos de usuários, área que engloba as pesquisas sobre comportamento informacional e outros campos. Nesse sentido, Rodrigues e Cardoso (2017) realizaram revisão sistemática de literatura no campo dos estudos de usuários, identificando os descritores que eram utilizados pelos próprios autores para definir os assuntos de suas pesquisas, enfatizando as produções nacionais com o objetivo de verificar o estágio atual das pesquisas brasileiras no campo. O termo "comportamento informacional" foi um dos que tiveram maior ocorrência, o que detona então a importância da área.

A partir do que foi discutido acima e daquilo que foi levantado na BRAPCI, deduz-se que a área de comportamento informacional tem se estabelecido cada vez mais dentro da Ciência da Informação como um campo prolífico e importante para os estudos de usuários.

\section{CONSIDERAÇÕES FINAIS}

O conceito de comportamento informacional tem sido adotado no âmbito da Ciência da Informação voltando-se para questões relacionadas à busca e o uso da informação pelos sujeitos. Por esse motivo, percebe-se que diversas influências nas abordagens da temática 
estão localizadas em tendências desenvolvidas num primeiro momento na subárea dos estudos de usuários.

A partir do levantamento realizado nesta pesquisa, notou-se que os estudos sobre comportamento informacional desenvolvidos por T. D. Wilson ganharam largo espaço na Ciência da Informação, contribuindo com a transformação das concepções existentes sobre o papel do sujeito nos processos de busca e uso da informação. O foco, que no início estava localizado em questões objetivas, se expandiu para abarcar o modo como os usuários enquanto indivíduos constituídos de fatores subjetivos, sociais e culturais - buscam e usam informação.

A relevância do tema para a Ciência da Informação pode ser percebida com base na quantidade de publicações que versam sobre comportamento informacional na principal base brasileira de dados da área: a BRAPCI. Nesse sentido, com base nos resultados do levantamento realizado nesta pesquisa, é possível notar que a partir de 1997 houve certa ascensão da temática, mesmo não sendo uma variante inflexível, visto que em alguns anos a quantidade de artigos sobre o tema foi maior ou menor que o ano anterior.

Com base no exposto, apesar de não ser o único autor a abordar o tema, T. D. Wilson é, com efeito, uma importante referência no que tange aos estudos em comportamento informacional, sendo citado em mais da metade dos artigos recuperados na BRAPCI. Suas discussões e modelos são ainda grande fonte de pesquisas teóricas e aplicadas. A ampla aceitação e adoção da abordagem de T. D. Wilson na Ciência da Informação revela tanto a relevância do autor, como também assinala a possibilidade de inspiração no desenvolvimento de investigações relacionadas à busca e uso da informação.

\section{REFERÊNCIAS}

ARAÚJO, Carlos Alberto Ávila. Estudos de usuários conforme o paradigma social da ciência da informação: desafios teóricos e práticos de pesquisa. Informação \& Informação, v. 15, n. 2, p. 23-39, jul./dez. 2010.

BERTI, Ilemar Christina Lansoni Wey; ARAÚJO, Carlos Alberto Ávila. Estudos de usuários e práticas informacionais: do que estamos falamos? In: SEMINÁRIO EM CIÊNCIA DA INFORMAÇÃO, 7., 2017, Londrina. Anais [...]. Londrina: UEL, 2017, p. 414-424. 
CAVALCANTE, Ricardo Bezerra et al. Comportamento informacional de gestores da rede Hiperdia Minas. Perspectiva em Ciência da Informação, v. 22, n. 3, p. 33-55, jul./set. 2017.

CAPURRO, Rafael. Epistemologia e ciência da informação. In: ENCONTRO NACIONAL DE PESQUISA EM CIÊNCIA DA INFORMAÇÃO, 5., 2003, Belo Horizonte. Anais [...]. Belo Horizonte: ENANCIB, 2003.

CHOO, Chun Wei. Como ficamos sabendo - um modelo de uso da informação. In: CHOO, Chun Wei. A organização do conhecimento: como as organizações usam a informação para criar significado, construir conhecimento e tomar decisões. São Paulo: SENAC, 2003. p. 63-120.

CORRÊA, Maurício de Vargas; ROZADOS, Helen Beatriz Frota. Comportamento informacional em comunidades virtuais: um estudo netnográfico do grupo de interesses SEER/OJS in Brazil no Facebook. Biblionline, João Pessoa, v. 12, n. 3, p. 112-125, jul./set., 2016.

CUNHA, Murilo Bastos da; AMARAL, Sueli Angelica do; DANTAS, Edmundo Brandão. Manual de estudo de usuários da informação. São Paulo: Atlas, 2015.

FERREIRA, Sueli Mara Soares Pinto. Novos paradigmas e novos usuários de informação. Ciência da Informação, Brasília, v. 25, n. 2, 1995.

FIALHO, Janaina Ferreira; ANDRADE, Maria Eugênia Albino. Comportamento informacional de crianças e adolescentes: uma revisão da literatura estrangeira. Ciência da Informação, Brasília, v. 36, n. 1, p. 20-34, jan./abr. 2007.

GANDRA, Tatiane Krempser; DUARTE, Adriana Bogliolo Sirihal. Estudos de usuários na perspectiva fenomenológica: revisão de literatura e proposta de metodologia de pesquisa. Informação e Sociedade: Estudos, João Pessoa, v. 22, n. 3, p. 13-23, set./dez. 2012.

GASQUE, Kelley Cristina Gonçalves Dias; COSTA, Sely Maria de Souza. Evolução teórico-metodológica dos estudos de comportamento informacional de usuários. Ciência da Informação, Brasília, v. 39 n. 1, p. 21-32, jan./abr. 2010.

GIL, Antonio Carlos. Métodos e técnicas de pesquisa social. São Paulo: Atlas, 2008.

MARCONI, Marina de Andrade; LAKATOS, Eva Maria. Metodologia do trabalho científico. São Paulo: Atlas, 2014.

MARTINEZ-SILVEIRA, Martha; ODONNE, Nanci. Necessidades e comportamento informacional: conceituação e modelos. Ciência da Informação, Brasília, v. 36, n. 1, p. 118-127, maio/ago. 2007.

NASCIMENTO, Natália Marinho do; VITORIANO, Maria Cristina Carvalho Pazin.

Comportamento informacional das organizações: a busca e o uso da informação no processo

PontodeAcesso, Salvador, v. 14, n. 1, p. 2-19, abr. 2020.

www.pontodeacesso.ici.ufba.br 
de avaliação documental. Ágora, Florianópolis, v. 27, n. 54, p. 126-157, jan./jun. 2017.

PIRES, Erik André de Nazaré. Comportamento informacional e processo de busca da informação: bases fundamentais para a pesquisa científica. Revista ACB, v. 17, n. 2, p. 288-307, jul./dez. 2012.

RODRIGUES, Virginia Lucia; CARDOSO, Ana Maria Pereira. O campo de estudos de usuários na ciência da informação brasileira: uma revisão sistemática da literatura. Em Questão, Porto Alegre, v. 23, n. 2, p. 234-251, maio/ago. 2017.

SANTOS, Andréa Pereira dos; CALDAS, Fernanda Correa. Comportamento informacional e avaliação de serviços bibliotecários. Informação em Sociedade: Estudos, João Pessoa, v. 26, n. 1, p. 91-101, jan./abr. 2016.

SAVOLAINEN, Reiko. Information Behavior and Information Practice: Reviewing the "Umbrella Concepts" of Information-Seeking Studies. The Library Quarterly: Information, Community, Policy, v. 77, n. 2, p. 109-132, abr. 2007.

WILSON, Thomas D. Human information behavior. Informing Science, v. 3, n. 2, p. 46-55, 2000. Special Issue on Information Science Research.

WILSON, Thomas D. Models in information behavior research. Journal of Documentation, v. 55, n 3, p. 249-270, June, 1999.

WILSON, Thomas D. On user studies and information needs. Journal of Documentation, v. 62, n. 6, p. 658-670, 2006. Artigo publicado originalmente no Journal of Documentation, v. 37, n. 1, p. 3-15, 1981. Foi incluído no v. 62, n. 6, p. 658-670, 2006 - edição consultada como parte de uma série de artigos republicados para celebração dos 60 anos das pesquisas em informação no Journal of Documentation. 